\title{
A Multi-color Electrochromic Material based on Organic Polymer
}

\author{
Hui Zhang ${ }^{1}$, Shouli Ming ${ }^{2}$, Yuzhang Liang ${ }^{1}$, Lei Feng ${ }^{1}$, Ting $\mathrm{Xu}^{1, *}$ \\ ${ }^{1}$ College of Engineering and Applied Sciences, Nanjing University, Nanjing 210093, China \\ ${ }^{2}$ State Key Laboratory Base of Eco-chemical Engineering, College of Chemistry and Molecular \\ Engineering, Qingdao University of Science and Technology, Qingdao 266042, China \\ *E-mail: xuting@nju.edu.cn
}

doi: $10.20964 / 2020.02 .30$

Received: 8 September 2019 / Accepted: 18 November 2019 / Published: 31 December 2019

\begin{abstract}
With low-cost and simple processing, organic electrochromic polymers have attracted considerable attention as a promising material platform for flexible and low-energy-consuming optoelectronic devices. However, typical electrochromic polymers can only be switched from natural-colored to oxidized-transparent states. As a result, the complexity of combining several distinct polymers to achieve a multi-color gamut has significantly limited the niche applications of electrochromic polymers. Here we report an electrochromic polymer based on 5,7-bis(3,3-dimethyl-3,4-dihydro- $\mathrm{H}$-thieno[3,4$b][1,4]$ dioxepin-6-yl)-2,3-dihydrothieno[3,4-b][1,4]dioxine (PEP), which exhibits multi-color reversible tuning capability. This organic electrochromic material offers an effective approach to dynamic manipulate color and enables a variety of optoelectronic applications.
\end{abstract}

Keywords: multi-color; color tuning; single molecular template; conjugated polymer; electrochromic material

\section{$\underline{\text { FULL TEXT }}$}

(C) 2020 The Authors. Published by ESG (www.electrochemsci.org). This article is an open access article distributed under the terms and conditions of the Creative Commons Attribution license (http://creativecommons.org/licenses/by/4.0/). 